\title{
Diferencia de precios entre las distintas marcas de medicamentos y los medicamentos genéricos Comentario de estudio hecho por ANADEUS ${ }^{1}$
}

\author{
DIFFERENCE IN PRICE BETWEEN DIFFERENT PHARMACEUTICAL BRANDS \\ AND GeNERICS. COMMENTS ON A STUDY CARRIED OUT bY ANADEUS
}

Este estudio llevado a cabo por esta asociación de consumidores tiene una serie de elementos particulares y dignos de relevar.

$\mathrm{Al}$ igual que otros estudios de comparación de precios de medicamentos, como los que confecciona Sernac periódicamente ${ }^{2}$, toma una muestra de medicamentos para poder comparar sus precios entre las diferentes farmacias objetivo. La primera diferencia es que en la selección de la muestra se utilizaron criterios no sólo económicos, lo que permitió la incorporación de orientaciones epidemiológicas, esto es incluyendo medicamentos utilizados para el tratamiento de las enfermedades más prevalentes en Chile. Esto lo convierte en un estudio más atractivo desde el punto de vista de la salud pública.

Otro aspecto relevado en el estudio es la diferencia que existe entre los medicamentos que se venden, destacando tres grupos:

1. Medicamentos Nuevos o Innovadores (con Marca)

2. Medicamentos Similares, o también conocido como "genérico de marca" (con Marca)

3. Medicamentos Genéricos (sin Marca)

Esta diferenciación es muy importante para una comparación de precios, ya que podemos encontrar con un mismo principio activo, tres "tipos de medicamentos", que a su vez tienen distintos públicos objetivos y por ende precios asociados.

Jorge Cienfuegos

Químico-Farmacéutico INE jorgecienfuegos@gmail.com
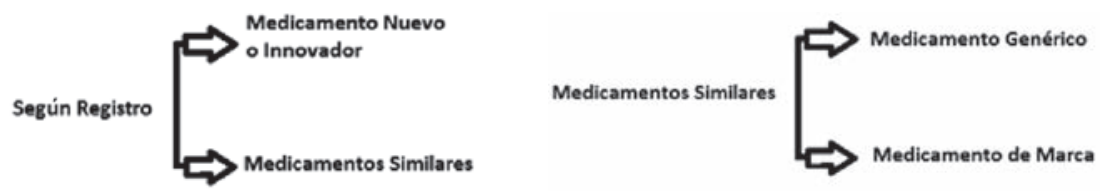

1. Asociación Nacional de Defensa de los Derechos de los Consumidores y Usuarios de la Seguridad Social.

2. http://www.sernac.cl/wp-content/uploads/2013/02/reporte-medicamentos-rmenero-2013.pdf. 
Aquí cabe una discusión ética importante, ya que como se presenta en el estudio: “...las principales empresas farmacéuticas que comercializan medicamentos genéricos en Chile, también son propietarias de similares de marca...", lo que produce una distorsión del mercado, cuando un laboratorio con un medicamento con exactamente el mismo principio activo puede $-\mathrm{y}$ lo hace- colocar y posicionar una marca que tenga los mismas características del medicamento genérico. Esto no implica ninguna mejora para el paciente (ni terapéutica ni económica). Se trata de un importante "riesgo moral" (moral hazard) en donde "...se estaría incurriendo en publicidad engañosa, al vender un mismo producto con diferente envase y a distinto precio. Médicos y autoridades se convierten en cómplices de este daño a las personas."

Las conclusiones del estudio presentan un panorama conocido por los profesionales de la salud, que en ocasiones pasamos a formar parte de este engaño colectivo, en forma directa, recibiendo incentivos de parte de laboratorios, o indirecta, al no exigir una política farmacéutica que propenda a medicamentos de igual efecto terapéutico a precios asequibles o "justos". Desnuda una realidad que lleva instalada en nuestro país bastante tiempo, y pone en tela de juicio no sólo a los profesionales de la salud, sino también a los técnicos de salud (dependientes de farmacias) y a la autoridad sanitaria, la cual no ha podido -de manera eficaz- abordarlo de manera exitosa, teniendo en conocimiento que "Los mercados de medicamentos tienden a ser muy imperfectos, es decir, a no garantizar por sí mismos acceso a los medicamentos para todos los que los necesitan, de modo que no son equitativos ni eficientes"3.

El estudio (con o sin querer) entra a la arena política, entendiéndose por tal, una preocupación que me parece legítima sobre los conflictos de poder entre los actores que integran el "mercado de los medicamentos", una autoridad sanitaria que no regula y lo más importante, consumidores (o pacientes, como nos gusta denominarlos a la gente del área de la salud) que bajo una asimetría importante de información quedan indefensos.

Se está avanzando con medidas como la bioequivalencia, pero para recuperar la confianza en un mercado farmacéutico cuestionado hay que buscar una mayor transparencia, y por sobre todo una política de medicamentos que dependa del MINSAL y la Superintendencia de Salud (ya que las farmacias actualmente no son consideradas dentro de esta última), y no sólo a través del

3. http://apps.who.int/medicinedocs/en/d/Jh2958s/ 